\title{
Forensic Photography: Concepts and Applications for better crime scene examination
}

\author{
Mendis NDNA* \\ Department of Forensic Medicine \& Toxicology, Faculty of Medicine, University of Colombo, Sri Lanka.
}

\begin{abstract}
Introduction
Forensic Photography is the fair and accurate recording of a scene or object, of legal interest, by a camera. "Photography is a valuable tool for recording the crime scene and explaining the evidence to others". The objective of forensic photography is to record an event, a scene, or an object correctly. It is always better to go for a good digital camera with an interchangeable lens. The physical size and quality of the image sensor along with the corresponding optics play a much bigger role in image quality than megapixels alone. Basic idea about exposure, depth of field and framing a shot is important to take a proper photograph. Photography is an important tool in most forensic examinations. Equipping all medico-legal units with necessary photographic equipment and providing a trained photographer is a very important action regarding the development of the field.
\end{abstract}

Keywords: Forensic Photography, digital camera, interchangeable lens, exposure, depth of field

Received: 10 May 2021, Revised version accepted: 27 June 2021, Published: 30 June 2021. *Corresponding author: Mendis NDNA, $\triangle$ Email: asela@fortox.cmb.ac.lk, (D) https://orcid.org/0000-0002-4690-9493

Cite this article as: Mendis NDNA. Forensic Photography: Concepts and Applications for better crime scene examination. Medico-Legal Journal of Sri Lanka, 2021;9(1):47-49. DOI: http://doi.org/10.4038/mljsl.v9i1.7429

Copyright: @ 2019 with the Medico-legal Journal of Sri Lanka.

This is an open-access article distributed under the terms of the Creative Commons Attribution 4.0 International License, which permits unrestricted use, distribution and reproduction in any medium provided the original author and source are credited.

\section{Introduction}

It will not be farfetched to say that digital photography has revolutionized photography and brought it mainstream into the hands of common people. With mobile phones, cheap cameras and computers in homes, capturing memories is not a difficult task anymore. However forensic photography is not just an exercise of taking beautiful photos - it is an exercise which reproduces various forensically and legally important facts as permanent record and piece of evidence.

When a photograph of a forged document was presented and allowed as courtroom evidence in 1851 photography as a forensic tool was born and soon became a boon to cases of identification and scene analysis.[1] Since then, it has grown from strength to strength and now become an essential part of forensic investigation.

A photograph will be admissible in courts only if it is a 'fair and accurate' representation of the subject in question. [2] For more than 150 years since forensic photography was considered as evidence in the court of law photographers have had many difficulties in explaining various facts about photographs including technical aspects. However, no one can produce an image 'as seen' by someone else. No one will be able to accurately document an item, scene or a moment someone else saw it.[3]
Due to the lack of knowledge, very often photography of crime scenes and other forensic events is done in a wrong manner and ultimate results are rendered useless. Forensic Photography is the fair and accurate recording of a scene or object, of legal interest, by a camera. The photographic documentation of crime scenes is the cornerstone of any criminal investigation.[4] Photography is a valuable tool for recording the crime scene and explaining the evidence to others.[5] "The objectives of crime scene photography are to record the conditions of the scene before alteration, record the location and position of evidence items collected, document the point of view of principals and potential witnesses, and document spatial relationships of pertinent items.".[6]

\section{Objectives}

The Objective of this paper to reiterate the importance of correct use of photography for forensic purposes.

\section{Discussion}

For most people photography is a hobby. Therefore, the outcome of their exercise depends on their expectations. Most people are happy to find a photo that has captured a general description of the object or the event they observed. However, this is far from the truth about forensic photography. The objective of forensic photography is to record an event, a 
scene or an object correctly which is an almost exact reproduction of the facts noticed at a scene that could be used for referral evaluative and evidential purposes. Photographs are statements of what he or she saw at a scene.[7] Therefore, each medico-legal unit should have essential basic photography equipment and a person with the necessary technical skills and knowledge. To achieve the said objectives one should have the following requirements fulfilled.

1. Essential photographic equipment

2. Basic knowledge about cameras and their use.

3. Use of photography software

4. Principles of the crime scene and forensic photography

5. Knowledge about the expectation of forensic photography

Essential photographic equipment: As film cameras are now considered outdated no one would even think about purchasing a film camera nowadays but if available using an SLR film camera is still acceptable. However digital cameras have many advantages over a film cameras. To mention a few when using a digital camera, one could instantly preview the photo just taken and therefore will be able to decide on taking a second shot or a shot from a different angle. Changing a memory card is far easier than loading a film roll into a camera. The capacity of the memory card is usually very high compared to the film roll. Generally, the maximum number of shots that could be taken using a film roll is 36 but a 16GB high speed card could store close to 1000 photos in fine jpeg format. On the other hand, the memory card can be reused many times.

Choosing a camera to achieve this task could be a difficult task. Generally, the decision depends on various facts including the budget you can spend. It is always better to go for a Digital Single Lens Reflex (DSLR) camera with an interchangeable lens. The number of megapixels in a camera is a misnomer about the quality of the photograph taken with a particular camera. A camera with a higher number of pixels generally gives a good photo than a camera with less number of pixels but within a certain range this change cannot be appreciated by a naked eye. Do not judge a camera solely on its megapixel count. The physical size and quality of the image sensor along with the corresponding optics play a much bigger role in image quality than megapixels alone, so do not be misled that megapixels will produce better photographs.

The following camera equipment would fulfil the basic need for a forensic photography unit.[4]

DSLR Full-frame camera body - 1, DSLR body (preferably with a swirling viewfinder) - 1, Lenses; short zoom lens $18-55 \mathrm{~mm}$ or similar range, long zoom 70 - $300 \mathrm{~mm}$ or similar range, wide-angle (add a hyphen between these 2) lens (e.g., 14mm.), macro $105 \mathrm{~mm}$, Dedicated Through The Lens metering (TTL) flashgun, Tripod/monopod (preferably both), Dry box or cabinet.

Basic knowledge about cameras and their use: A basic idea about exposure, depth of field and framing a shot is important to take a proper photograph. Use of this knowledge on photography basics should be correctly done to take a properly focused, properly exposed and correctly framed photo so that it would depict the correct representation of what was there in the crime scene. Exposure bracketing is another method that could be used to achieve properly exposed photos.[8] A flashgun should be used appropriately to record the scene properly. Most people do not consider using the flash in daylight shooting but it might come in handy when capturing backlit objects or items found in dark shaded areas.

There is no prescribed length of time it takes to photographically document a crime scene. The time spent depends on the extent and complexity of the crime and crime scene. Maintaining a $\log$ of the photographs taken is important if they are to be used as evidence in the court of law. [9] Crime scene photography should not be focused only on the obvious. The purpose of taking photographs is to document the crime scene and to show whether it is connected to the crime. As one of the primary documentation components, a systematic, organized visual record of an undisturbed crime scene must be achieved. [10]

The photographer should be able to assess the conditions at the scene and use proper techniques in taking photographs. Another area that attention should be paid is when you use the macro lenses for macro-photography. The technique and settings are different from normal photography. Depth of field is important in close-up photography because unless otherwise proper aperture setting is used photograph might turn up to be not clear enough.[11]

Photograph the scene as is before putting in scales and placards. [12] When taking photographs of evidence found a basic set of photographs should be taken of each item, with and without scale and colour code, general photographs showing it relationship to the scene and one shot of the location of evidence after the item has been moved or retrieved. Using the correct perspective and angle is also important in recording the scene properly.

Using photography software like adobe Photoshop or light room is accepted if you retained the original photograph as the proof and record all changes done chronologically. However, software usage in 
forensic photography mainly should be limited to enhancing technology like correcting the exposure, lighting etc. Deleting items of objects from the original photo or adding on of objects is not acceptable. It is always better to record the photos in both in RAW format (A RAW image (also known as a "digital negative") is an image file that contains unprocessed or minimally processed data) and JPEG (JPEG stands for Joint Photographic Experts Group) format where RAW format could be easily used for editing purposes.

There are few more basic principles that should be adhered to. If you are using a film camera a new film role should be used to capture each new scene. In digital photography, the memory card could be reused but before photographing each new scene card should be formatted so there will not be any photographs unrelated to the scene remaining in the card.

\section{Conclusions}

Photography is an important tool in most forensic examinations. Therefore, developing standard operating procedures for forensic photography and equipping all medico-legal units with necessary photographic equipment and providing a trained photographer is a very important action regarding the development of the field.

It is not difficult to master or at least to be somewhat competent with. If the unit does not have a designated photographer knowing the basics of photography and crime scene photography might become handy at a time most unexpected and important.

\section{Disclosure statement \\ Conflict of Interests: None \\ Acknowledgements: None \\ Funding: None}

\section{References}

1. Davis, P., 1995. Photography, seventh ed. McGraw-Hill, Boston.

2. Aric Dutelle, An Introduction to Crime Scene Investigation., 2nd Edition. Jones \& Bartlett Publishers, 2014. ISBN-13: 978-1284048179.

3. Aric W. Dutelle, MFS, Basic Crime Scene Photography, 2nd Edition. An Amazon.com Company, 2016. ISBN-13: 978-1514334331, ISBN-10: 151433433X

4. Christopher D. Duncan, Advanced Crime Scene Photography, CRC Press. Taylor \& Francis Group. 2010. ISBN: 978-1-4200-8789-5

5. Staggs, Steven. 2nd. Ed. Crime Scene and Evidence Photographer's Guide. Wildomar, CA: Staggs Publishing, 2004.
6. Ogle, Robert R., Jr. Crime Scene Investigation and Reconstruction. Upper Saddle River, NJ: Pearson Education, Inc., 2004.

7. Miller, Larry L. 3rd ed. Sansone's Police Photography. Cincinnati, OH: Anderson Publishing Co., 1993.

8. McHugh, Sean. Understanding Depth of Field. Cambridge in Color. (Accessed December 14, 2016)

http://www.cambridgeincolour.com/tutorials/de pth- of field.htm.

9. Gardner, Ross M. Practical Crime Scene Processing and Investigation. Boca Raton: CRC Press, 2005.

10. Lee, Henry C., et. al. Henry Lee's Crime Scene Handbook. New York: Academic Press, 2001.

11. Nick Marsh, Forensic Photography A Practitioner's Guide. John Wiley \& Sons, Ltd, 2014. ISBN: 9781119975823

12. Ronald F. Becker. 2nd ed. Criminal Investigation. Boston: Jones and Bartell Publishers, 2005. 